\title{
O PLANEJAMENTO FAMILIAR NO BRASIL NO CONTEXTO DAS POLİTICAS PÚBLICAS DE SAÚDE: DETERMINANTES HISTÓRICOS*
}

\author{
FAMILY PLANNING IN BRAZIL IN THE CONTEXT OF PUBLIC HEALTH \\ POLICIES: IMPORTANT HISTORICAL FACTORS
}

\begin{abstract}
Edméia de Almeida Cardoso Coelho** Maria de Fátima Gomes de Lucena*** Ana Tereza de Medeiros Silva****
\end{abstract}

COELHO, E. A. C. et al. O planejamento familiar no Brasil contexto das políticas de saúde: determinantes históricos.

Rev.Esc.Enf.USP, v. 34, n. 1, p. 37-44, mar. 2000.

\section{RESUMO}

O presente estudo faz um resgate histórico da formulação e implementação das politicas públicas de saúde no Brasil, com ênfase na politica de planejamento familiar. Conclui que, esta, em seu início, atendeu a interesses controlistas internacionais e hoje, o planejamento familiar, embora oficialmente reconhecido como direito de cidadania, ainda reflete interesses contraditórios das instâncias politicas, econômicas e ideológicas de poder.

PALAVRAS-CHAVE: Planejamento familiar. Políticas de saúde. Saúde da mulher.

\begin{abstract}
This study searches historical records for the formulation and implementation of public health policies in Brazil, focusing on those referent to family planning. Initial conclusions show that the policies were geared toward international controlling interests. Family planning today, though officially recognized as an inalienable right of every citizen, still reflects the contradictory political, economic and ideological interests of the ruling power.
\end{abstract}

KEYWORDS: Family planning. Public health policies. Women's health.

\section{INTRODUÇÃO}

A idéia de uma medicina social surgiu durante a Revolução Francesa, no século XVIII, porém, foi a Inglaterra que criou os primeiros mecanismos para transformá-la em uma política de Estado. No Brasil, a saúde como questão social surgiu na década de 20 durante a expansão da economia cafeeira, período de formação da sociedade capitalista. Nessa época, o aumento da população era necessário para expansão da economia mas, como a inserção no mercado de trabalho não era garantida a todos economicamente ativos e como as cidades cresceram sem uma política sanitária básica, expandiram-se a pobreza, as doenças e a marginalização, e a questão populacional foi se constituindo como um problema político.

Nas primeiras décadas do século XX, surgiram na Europa e nos Estados Unidos movimentos de caráter malthusiano que associavam a miséria ao crescimento populacional. Ao longo do processo de consolidação da sociedade capitalista o Estado brasileiro adotou uma postura pró-natalista, mas, principalmente, a partir dos anos 60, pressões americanas forçaram a entrada de entidades internacionais no Brasil, que tinham como

Artigo produzido a partir da Dissertação de Mestrado:COELHO, E. de A C. Política de planejamento familiar em João Pessoa PB: análise das contradições existentes entre o discurso oficial e a prática, João Pessoa, 245 p. Dissertação (Mestrado), Universidade Federal da Paraíba, 1996.

** Enfermeira, Mestra em Enfermagem de Saúde Pública, Professora Assistente III do Departamento de Enfermagem de Saúde Pública e Psiquiatria da Universidade Federal da Paraíba, aluna do Programa Interunidades de Doutoramento em Enfermagem da Escola de Enfermagem da USP.

*** Assistente Social, Doutora em Ciências Sociológicas, Professora adjunto do Departamento de Serviço Social da Universidade Federal de Pernambuco.

**** Enfermeira, Mestre em Enfermagem, Professora adjunto IV do Departamento de Enfermagem de Saúde Pública e Psiquiatria da Universidade Federal da Paraíba. 
principal objetivo controlar o crescimento populacional dos países pobres. Assim, os anticoncepcionais entram no mercado e as mulheres, uma vez conseguindo dissociar sexualidade de procriação, aderem principalmente à contracepção hormonal mas, sem assistência adequada, comprometem a sua saúde e tornam-se cada vez mais dependentes do sistema médico. No final da década de 70 , passam a defender a regulação da fecundidade como direito de cidadania reivindicando o controle sobre o corpo e contestando os interesses controlistas.

Em 1983, essa reivindicação feminista foi atendida oficialmente através do Programa de Assistência Integral da Saúde da Mulher (PAISM), em seu sub-programa planejamento familiar*. Este tem como pressuposto básico o reconhecimento de que "todas as pessoas têm o direito à livre escolha dos padrões de reprodução que lhes convenham como individuos ou casais" (BRASIL, 1987). E, "para que esse direito possa ser efetivamente exercido, é necessário que os indivíduos tenham conhecimento das possibilidades de influir no ritmo da procriação e tenham acesso às informações e aos meios para que possam intervir, se assim o desejarem, para separar o exercício da sexualidade da função reprodutiva e, em conseqüência, exercer na plenitude o planejamento de sua prole ..." (BRASIL, 1985).

No nosso cotidiano profissional, atuando no serviço de pré-natal e maternidade de um hospital público em João Pessoa - PB, no período posterior à criação do PAISM, assistimos a um número significativo de mulheres, que estão grávidas de filhos indesejados, enfrentando as complicações de abortamentos provocados e, outras vezes, "aceitando" a condição de gestantes ou de mães, por estarem cumprindo a função feminina da reprodução.

Em virtude do desacordo entre a proposta teórica do PAISM e a realidade concreta das mulheres referidas, optamos por desenvolver uma pesquisa, com o objetivo de analisar as contradições existentes entre o discurso oficial e a prática concreta no que se refere à política de planejamento familiar em João Pessoa - PB, no momento em que esta politica de saúde, oficialmente, completava 10 anos. Tendo em vista ser a regulação da fecundidade uma questão enfrentada por forças sociais divergentes, decidimos realizar a revisão bibliográfica como etapa anterior à pesquisa de campo, visando conhecer os determinantes históricos das políticas de planejamento familiar no Brasil.

Para atingir o objetivo nos propomos a responder às seguintes questões: a - Qual o contexto sócio-político do Brasil por ocasião da elaboração das políticas de planejamento familiar?

b - Quais as forças e os determinantes políticos que motivaram a formulação do PAISM?

Este artigo refere-se à primeira etapa da Dissertação de Mestrado : "Política de planejamento familiar em João Pessoa - PB: análise das contradições existentes entre o discurso oficial e a prática"; a segunda etapa consiste no trabalho de campo, o qual resultou em outro artigo, que manteve o título da Dissertação.

\section{REPRODUÇÃO HUMANA E AS POLÍTICAS DE SAÚdE NO BRASIL NO INÍCIO DO SÉCULO}

A organização social brasileira desde a Colônia foi estruturada a partir do setor agrícola, necessitando-se de familias numerosas nos latifúndios para aumentar a produção. Nos minifúndios também era nítida essa necessidade, porém, para garantir a subsistência da familia, com a qual se contava na velhice e na doença. BRAGA; PAULA (1986) informam que, nesse início de século, os índices de morbi-mortalidade eram altos e, diante da precariedade das condições de saúde, o Presidente Rodrigues Alves lançou um programa de obras públicas para saneamento do Rio de Janeiro. Em 1903, Oswaldo Cruz iniciou o combate à febre amarela urbana e, posteriormente, foram lançadas medidas de combate à malária e a obrigatoriedade da vacina contra a varíola

As medidas sanitárias dessa época ocorriam sob a forma de campanhas e tinham caráter jurídico, impondo-se notificação de doenças, vacinação,obrigatória e vigilância sanitária, que não passavam de soluções imediatistas. Tinham como objetivo diminuir a mortalidade geral para manter o processo de acumulação cafeeira, a política de imigração, bem como manter a insatisfação popular sob controle. Com a aceleração da urbanização e do desenvolvimento industrial, a saúde cresceu como questão social e a cobertura da assistência foi ampliada com a Reforma Carlos Chagas.

O final dos anos 20 foi marcado por uma crise política que culminou com a derrubada do governo por uma junta militar, sendo o poder central assumido por Getúlio Vargas na década seguinte. BRAGA; PAULA (1986) afirmam que, nos anos 30, o Estado passou a ser mais autônomo, rompendo-se a estrutura de poder da

\footnotetext{
Neste estudo, ao nos referirmos ao planejamento famililar, o entendemos como o exercício do direito da mulher ou do casal à informação, à assistência especializada e ao acesso a todos os recursos que lhes permitam a opção livre e consciente por ter ou não ter filhos, pelo espaçamento e número de gestações e pelo método anticoncepcional mais adequado aos seus desejos e condições orgânicas, sem coação de qualquer origem.

Ao nos referirmos a controle da natalidade, o entendemos como a interferência do Estado sobre a vida da mulher ou da família induzindo-a a controlar a sua capacidade reprodutiva pela diminuição da prole, por razões de ordem politica, social, econômica ou demográfica, quer através de uma politica oficial de população, quer por mecanismos indiretos, tais como: interferência externa por pressões políticas; atuação de ONGs (Organizações-Não -Governamentais); interesses elleitoreiros.
} 
Primeira República. Para FALEIROS (1992) Vargas praticava o clientelismo pela subvenção às instituições de assistência, realização de obras sociais e apoio a organizações religiosas e sua política levou o país a uma crise econômica que o governo tentou a todo custo controlar.

O aumento da massa trabalhadora em precárias condições de higiene, saúde e habitação, decorrente da industrialização e da urbanização, pressionou o governo a ampliar as politicas sociais, resultando em uma política de saúde, organizada em dois subsetores - o da Saúde Pública e o da Medicina Previdenciária. Nos anos 30 iniciou-se a centralização da política de saúde, sendo criado o Ministério da Educação e Saúde; foi promulgada a Nova Constituição; foram retomadas as campanhas sanitárias como ações coordenadas centralmente, constituindo elementos importantes no processo de centralização da política nacional de saúde (BRAGA; PAULA, 1986); e, em 1937, foram instituídas as Conferências Nacionais de Saúde pela Lei n. 378 de 13 de janeiro (NASCIMENTO, 1991).

$\mathrm{Na}$ década de 40, vários serviços de atenção primária foram criados, como o de combate à febre amarela, que, segundo FALEIROS (1992) teve apoio americano, por interesses na produção de borracha na Amazônia e do manganês no Vale do Rio Doce; e o Serviço Especial de Saúde Pública (SESP) que, para o autor citado, teve como razão principal o interesse dos Estados Unidos em vencer a resistência de Vargas e fazer o Brasil entrar na Segunda Guerra Mundial, passando o governo americano a ter estreita relação com o governo brasileiro, ajudando-o nas questões cruciais em relação à saúde. Nesse período, o Ministério da Educação começou a investir na formação de técnicos de saúde pública. Estas medidas constituíram as bases para a criação do Ministério da Saúde, em 1953.

Apesar da organização estrutural do setor saúde e das medidas adotadas nessas primeiras décadas do século XX, os índices de mortalidade, em especial, a morbi-mortalidade infantil e materna continuaram altos, principalmente até os anos 40. Segundo SOUZA (1978), "nos períodos compreendidos entre 1870 e 1940, as taxas de mortalidade eram de tal magnitude que, apesar de mantido o padrão da família numerosa especialmente nas áreas rurais - o crescimento da população mostrou-se menos acentuado do que nas duas décadas sucessivas de 40 e 50".

Enquanto no Brasil buscava-se preservar a natalidade, no final do século XIX surgiram na Europa e nos Estados Unidos os primeiros movimentos de controle da natalidade. A propaganda contraceptiva tinha conotação política, inspirando-se seus defensores na Teoria de Malthus, segundo a qual quanto mais crescesse a população, mais pobre ela seria, pois esta crescia em progressão geométrica e os alimentos em progressão aritmética. Malthus baseou-se no crescimento da pobreza a partir da Revolução Industrial, sem considerar as circunstâncias em que esta ocorria.

$\mathrm{Na}$ primeira década deste século, Margareth Sanger, líder feminista, iniciou nos Estados Unidos um movimento pelo direito à regulação da fecundidade, juntamente com socialistas e anarquistas americanos, chamado "birth control". Sanger mostrava-se sensivel às queixas das mulheres por razões social, econômica ou de saúde, somando-se a essas necessidades, transformações resultantes da industrialização e da urbanização que as despertaram para reivindicar o direito à educação, ao voto e à regulação da fecundidade. $\mathrm{Na}$ Europa, especialmente na Inglaterra, o movimento foi liderado por Marie Stopes (RODRIGUES, 1990). Três linhas de pensamento foram formadas nesse período: a das feministas, que consideravam a contracepção um direito fundamental da mulher; a dos neomalthusianos que a defendiam como meio para melhorar a situação da pobreza; e a dos eugenistas, que viam no controle da natalidade um caminho para melhorar a qualidade genética (AVILA, 1992). No Brasil, diante da postura prónatalista, os movimentos internacionais não ecoaram nessas primeiras décadas do desenvolvimento capitalista.

\section{O PÓS-GUERRA E A QUESTÃo POPULACIONAL}

No Brasil, o pós guerra foi marcado por grande expansão industrial e, em 1953, esta já .ultrapassava em $50 \%$ o crescimento da agricultura. No governo Juscelino Kubistchek, o capital estrangeiro passou a entrar maciçamente no país com o fim de fornecer tecnologia avançada e ampliar mercados consumidores. Apesar da expansão e modernização da indústria, a distribuição de renda continuou perversa e desigual e, tal política fez surgir um surto inflacionário, que passou a ser objeto de luta e mobilização dos trabalhadores (FALEIROS, 1992).

A mortalidade geral diminuiu em relação às décadas anteriores, mas a natalidade continuou alta. Governos e estudiosos começaram a se preocupar com o crescimento populacional, argumentando que "os recursos existentes no mundo não seriam suficientes para manter a população global, caso continuasse a crescer no mesmo ritmo" (SEMPRE VIVA ORGANIZAÇÃO FEMINISTA-SOF, 1994). Em torno de 1960, os países ricos, especialmente os Estados Unidos, que já tinham os países pobres sob sua dependência, passaram a pressionar governos do Terceiro Mundo para adotar uma politica de população, inspirados nas idéias de Malthus. Consideravam haver nos países ricos uma estabilidade no crescimento 
populacional e nos pobres uma explosão populacional, atribuindo a ela a responsabilidade pela fome, pela pobreza, pela degradação do meio ambiente e, sendo assim, a redução do crescimento populacional deveria ser a principal prioridade para os planos de desenvolvimento (SOF, 1994).

No início dos anos 60, o governo americano passou a pressionar o Brasil para que adotasse uma política demográfica como critério para empréstimo (PACHECO, 1981). Nessa época, os movimentos sociais organizados contestaram, argumentando serem as conquistas sociais das mulheres e o desenvolvimento econômico do Primeiro Mundo condicionantes da diminuição da natalidade e não a relação inversa. Mas, a perspectiva controlista ampliou-se.

Nesse início de década, o contexto sócio-político e econômico do país refletia as exigências do Fundo Monetário Internacional (FMI) e o governo de Jânio Quadros foi conduzido segundo estas. No governo do seu sucessor, João Goulart, foram propostas reformas de base, incluindo-se o tema da municipalização, situação sanitária nacional e a Política Nacional de Saúde que se reverteriam em conquistas sociais (NASCIMENTO, 1991). Todavia, João Goulart não conseguiu organizar e unir as forças progressistas e enfrentar as insatisfações militares, as manifestações de rua e as greves. Enfraqueceu e foi derrubado pelos militares em 1964.

\section{A CONJUNTURA NACIONAL DURANTE A DITADURA MILITAR E O IMPACTO NO SETOR SAÚDE}

Durante a ditadura, o Estado utilizou a força militar para reprimir organizações populares e os comunistas. Os trabalhadores tiveram seus salários reduzidos, ampliando-se a exploração da mão-de-obra pelo aumento das horas de trabalho e pelo processo de acumulação do capital, possibilitando o Milagre Brasileiro. Nos anos 70 houve um desaquecimento da economia pela crise do petróleo e, na década seguinte, agravou-se a recessão econômica com a expansão da dívida externa (FALEIROS, 1992). Em se tratando das questões de saúde, apesar de até 1960 ter predominado a ênfase na Saúde Pública, esta basicamente foi centrada em campanhas e medidas sanitárias dirigidas a grupos isolados, que participavam diretamente do processo de acumulação capitalista.

Durante o Milagre Econômico, a medicina tornouse mais especializada e sofisticada. Criaram-se clinicas e hospitais particulares financiados pela Previdência Social, expandiram-se as faculdades particulares de Medicina e surgiu a medicina de grupos, através de um setor empresarial de proprietários de hospitais. Consolidou-se "uma relação autoritária, mercantilizada e tecnificada entre médico e paciente e entre serviço de saúde e população", constituindo as principais orientações da política sanitária da conjuntura do Milagre Brasileiro (LUZ, 1991).

A Medicina Previdenciária foi unificada em 1966 com a criação do Instituto Nacional de Previdência Social (INPS), quando enfrentava grave crise econômico-financeira, devido à mudança no caráter da prestação de serviços. Em 17 de Julho de 1975 foi promulgada a Lei 6229, criando o Sistema Nacional de Saúde, que estabeleceu para o Ministério da Saúde ações voltadas ao atendimento de interesse coletivo e para o Ministério da Previdência e Assistência Social, principalmente, o atendimento médico-assistencial individualizado No final da década, o governo reconheceu formalmente a crise previdenciária e criou o Sistema Nacional de Previdência e Assistência Social (SINPAS), objetivando reorganizar o Sistema (BRAGA; PAULA, 1986).

Todo o conjunto de medidas proposto para a assistência à saúde no período pós - 64, não conseguiu melhorar a saúde nem o padrão de vida da população carente, sendo que alguns indicadores de saúde pioraram. O pouco investimento na rede pública de saúde refletia a crise na Previdência, agravada pela capitalização da medicina, que exigia quantias cada vez maiores de dinheiro para cobrir os serviços prestados pela rede privada.

Somente ao final da década de 70, mais precisamente, no início dos anos 80 , ressurgiram os movimentos sociais que forçaram o processo de redemocratização do país, marcado por conquistas importantes. No âmbito da saúde, organizou-se o Movimento Sanitário exigindo soluções para os graves problemas sociais existentes.

\section{As politicas de assistência à mulher no contexto do estado militarista}

Uma vez dependente do capital internacional, o Brasil se rendeu às entidades americanas consideradas de planejamento familiar, apesar da resistência de militares, da Igreja e do próprio governo, que justificavam a importância de uma grande população, tanto do ponto de vista estratégico como econômico. Em 1965, no contexto de uma grave crise econômica e politica, foi criada a BEMFAM (Sociedade Civil de Bem-Estar Familiar no Brasil). Financiada por entidades internacionais e de interesses nitidamente controlistas facilitou o acesso das mulheres aos métodos contraceptivos, principalmente à pílula, através da distribuição gratuita, sem garantia de acompanhamento médico (RODRIGUES, 1990).

A década de 60 foi marcada pela maior inserção da mulher no mercado de trabalho, expansão da consciência feminista e chegada maciça dos métodos anticoncepcionais, como pilula e DIU. Coincide com 
uma cena política de contestação cultural, o que facilitou a aceitação pelas mulheres, principalmente da pílula, sendo os contraceptivos divulgados como instrumentos eficazes e imprescindiveis para a liberação feminina, permitindo dissociar a sexualidade da procriação. Segundo XAVIER et al (1989), as mulheres logo constataram que o acesso aos contraceptivos não conseguiu fazer com que deixassem de ser consideradas cidadãs e trabalhadoras de segunda categoria, os métodos estiveram cada vez mais sob controle médico, a oferta sempre foi limitada, precária e sem assistência adequada, comprometendo a sua saúde.

A BEMFAM foi considerada de utilidade pública pelo governo Médici. Em 1974, a politica demográfica do Brasil foi anunciada oficialmente na Conferência Mundial de População em Bucareste, onde o governo brasileiro declarou ser um direito social, decidir quanto à composição da família. Para tanto, o poder público deveria se ocupar da divulgação de informação sobre a contracepção, o que na prática não se efetivou.

As políticas de assistência à mulher passaram a ser melhor delineadas a partir de 1975, com o Programa Nacional de Saúde Materno-Infantil (PMI), criado após seis anos da recomendação da Organização Mundial de Saúde (OMS). Para efeito de determinação da população alvo, o grupo materno-infantil, a OMS orientou o critério da relação risco/classe social, considerando a importância biológica, sócio-econômica e numérica do grupo, sendo prioritário o mais pobre, mais carente, mais marginalizado, identificando claramente uma classe social. O PMI acelerou as especializações, a tecnificação, a concentração médica nos grandes centros urbanos, a prática hospitalar, a impessoalidade, a multiplicidade de empregos e uma prática médica curativa em detrimento da preventiva (MARQUES, 1978).

No PMI apresentavam-se também as possibilidades de orientação sobre o planejamento familiar, que já era defendido e praticado por um Programa anterior, o PEP (Programa Especial de Pediatria ). Neste, a mulher que já possuía número elevado de filhos e dispunha de escassos recursos para manter sua família, podia ter acesso à discreta orientação sobre o uso de contraceptivos (SOUZA, 1978). Para MARQUES (1978), o PMI também tinha um componente educativo e sendo dirigido à gestante, criança e adolescente, pretendia a transformação das atitudes, dos comportamentos, persuadindo a população pobre a modificar seu modo de vida, fazendo-a reconhecer que ela própria é responsável por seus problemas de saúde.

Até a década de 80 o debate sobre a reprodução humana era centrado no natalismo tradicional e no neomalthusianismo. Nessa década, o planejamento familiar foi contemplado pelo Prev-Saúde com ênfase à educação para a paternidade responsável, à obrigação do Estado quanto às informações sobre os métodos anticoncepcionais e à revisão da legislação sobre a fecundidade. O Prev-Saúde representava um projeto com grande investimento em assistência primária, mas não se efetivou por encontrar resistência entre proprietários de hospitais, representados pela Federação Brasileira de Hospitais, e na Associação Brasileira de Medicina de Grupo (NASCIMENTO, 1991).

Nos anos 80, saúde, habitação e educação estavam em crise e, em 1983, havia manifestações de rua reivindicando politicas sociais que assegurassem direitos de cidadania. $O$ país inteiro se mobilizou em torno da campanha para eleições diretas para presidência da República, disputando, como afirma NASCIMENTO (1991), um verdadeiro campeonato cívico, que tinha nos comícios a prova da vontade popular.

Naquela ocasião, o movimento de mulheres interveio no debate nacional sobre o planejamento familiar, "instituindo-se a noção de que a assistência à contracepção deveria compor uma política ampla de saúde reprodutiva, passando a questão reprodutiva a ser vista como decisão ética individual e um direito social" (CORREA, 1992). Esta visão era consenso entre os diferentes movimentos sociais, como o de mulheres, sanitaristas, demógrafos, cientistas sociais e militantes de partidos políticos, o que resultou na formulação do PAISM (Programa de Assistência Integral à Saúde da Mulher), em 1983.

O PAISM, adotado como política de assistência à saúde da mulher, tem como objetivo: atender a mulher, "através de atividades de assistência integral clínico-ginecológica e educativa, voltadas para o aprimoramento do controle pré-natal, do parto e do puerpério; a abordagem dos problemas presentes desde a adolescência até a terceira idade; o controle das doenças transmitidas sexualmente, do câncer cérvicouterino e mamário e a assistência para a concepção e a contracepção" (BRASIL, 1992). Com o PAISM as mulheres chegam à Nova República, acreditando num país que, finalmente, tinha reconhecido que as situações vividas ao longo do seu ciclo vital as tornavam merecedoras de atenção especial.

\section{OS CAMINHOS DO SISTEMA ÚNICO DE SAÚDE (SUS)}

A redemocratização do país permitiu que a idéia da criação de um Sistema Único de Saúde fosse discutida publicamente, sendo fortalecida no governo Figueiredo, ao lado de conquistas politicas como a anistia e a eleição direta para governadores em 1982. A $7^{\text {a }}$ Conferência Nacional de Saúde (CNS) caminhou nessa direção. Assumiu um caráter de 
reforma da Política Nacional de Saúde, sendo incorporados ao discurso do governo, temas como universalização da cobertura, atenção primária, hierarquização e regionalização, diminuindo assim as divergências entre o governo e o Movimento Sanitário.

Surgiram, a partir desta Conferência, as possibilidades de uma Reforma Sanitária que culminou com a 8a Conferência Nacional de Saúde (CNS), em 1986. A 8a CNS foi considerada como o "evento mais significativo no processo de construção da estratégia e da tática pela democratização da saúde em toda sua história" (NASCIMENTO, 1991). A partir dela, o governo reconheceu a necessidade de reestruturação do Sistema Nacional de Saúde através da criação de um Sistema Único de Saúde (SUS) que "efetivamente representasse a construção de um novo arcabouço institucional separando totalmente saúde de previdência, através de uma ampla Reforma Sanitária" (CONFERENCIA NACIONAL DE SAÚDE -CNS (1987).

Nessa década, foi criado o SUDS (Sistema Único Descentralizado de Saúde) por um decreto do Presidente Sarney. O SUDS incorporou os princípios da Reforma Sanitária, a universalização, a integralidade da atenção, a regionalização e a hierarquização, a descentralização do processo decisório, a democratização das instâncias gestoras e a questão da política integrada de recursos humanos. O SUDS facilitou a implementação das AIS (Ações Integradas de Saúde), iniciadas em 1983. Entretanto, por razões de ordem político-ideológica, ligadas a interesses da iniciativa privada e por erros estratégicos, o SUDS não atingiu os objetivos aos quais se propôs.

A Constituição de 1988 reconheceu a saúde como "direito de todos e dever do Estado" e contemplou a descentralização das ações e serviços de saúde entre os três niveis de governo, através do SUS. Ao iniciarse o governo Collor, havia no Brasil um novo arcabouço jurídico que orientava o Sistema de Saúde, tendo como referência a Constituição Federal.

A IX Conferência Nacional de Saúde (CNS) ocorreu durante a mobilização para o "impeachment" do então presidente Fernando Collor. Este, além de obstaculizar a realização da Conferência, apresentouse ao evento através do ministro Adib Jatene "sem projeto, sem diretrizes claras e sem realizações que pudessem revelar um eixo descentralizante" (DOCUMENTO, 1992).

$\mathrm{Na}$ realidade, enquanto se construía o processo de redemocratização do país, construía-se também, através de uma dinâmica oculta, mas de alta eficácia politica, o projeto neoliberal que instalou-se no país como um projeto conservador da saúde. Hoje, a conjuntura é contrária aos princípios do SUS, a saúde constitui um bem de consumo médico e continuam excluídos da assistência, milhões de brasileiros que financiam as politicas mas não usufruem delas.

\section{SUS e neoliberalismo: a difícil convivência}

As politicas neoliberais foram consolidadas inicialmente em economias européias, principalmente na Inglaterra, no governo de Margareth Thatcher. O neoliberalismo foi apontado como solução para diversos países da América Latina pelo Fundo Monetário Internacional (FMI), o Banco Mundial e o Banco Interamericano de Desenvolvimento (BID), numa reunião conhecida como Consenso de Washington, em 1989 (BEZERRA, 1995).

O projeto neoliberal propõe a diminuição da participação do Estado e, na saúde, as políticas neoliberais são definidas por CAMPOS (1990), como "o conjunto de medidas tomadas a partir de 1973 (...), nos países industrializados capitalistas, como conseqüência da aplicação de fórmulas econômicas de contenção do gasto público e congelamento salarial para solucionar a eufemisticamente chamada crise fiscal do Estado".

Nas décadas de 80 e 90 intensificaram-se os convênios com as seguradoras ou cooperativas de profissionais e, principalmente, com o Estado, através do SUS. Segundo LUCENA (1996), desde os anos 70 , "os convênios privados de saúde consomem quase a totalidade da parte da seguridade social destinada à saúde...", beneficiando assim, "... os trustes hospitalares, industriais e laboratórios, atendendo aos interesses dos grupos oligopólicos transnacionais e hegemônicos".

Hoje, no país, é nítida a predominância de uma medicina que atende à lógica neoliberal, com expansão da assistência à saúde mercantilizada, através de modalidades discriminatórias, fazendo com que a população tenha como referência o subsistema privado de saúde. Para o subsistema público são destinados recursos limitados e a assistência assume caráter filantrópico, negando a saúde como direito. Embora, atualmente, haja uma demanda crescente por parte da classe média, ainda é a classe pobre e politicamente menos combativa que mais se submete às mazelas de um serviço público que é paradoxalmente universal e excludente da maioria.

\section{O PLANEJAMENTO FAMILIAR NO CONTEXTO ATUAL DAS POLÍTICAS DE SAÚDE NO BRASIL}

A forma de encaminhamento das questões sociais durante a transição democrática conduziu a propostas consensuais e o PAISM insere-se nesse contexto, uma vez que é o resultado de uma luta política assumida por segmentos dos movimentos sociais dos anos 80 , especialmente o de mulheres.

O processo de implantação do PAISM e, Particular da política de planejamento familiar, vem 
sendo marcada mais por retrocessos do que por avanços. Segundo AVILA (1989), entre 1985 e 1987, houve uma tentativa de instituir um programa oficial de controle da natalidade no país. Um anteprojeto de Lei de abril de 1985 estabelecia uma política de população com fixação de taxas de aumento ou diminuição da população, prevendo a participação de entidades privadas com experiência na área, mas as pressões contrárias o fizeram sucumbir. A mesma autora também afirma que em 1987, o Conselho de Desenvolvimento Social deliberou como ação prioritária para solucionar o problema da pobreza a implantação de um programa de controle da natalidade mas, novamente, diante das reações da sociedade civil, o governo teve que recuar.

Em 1992, pesquisa nacional de avaliação do PAISM concluiu que "... a degradação qualitativa dos serviços de saúde agravada na última década, somada à ausência de priorização da saúde da mulher nas propostas de gestão, determinaram um caótico quadro da situação da assistência" (COSTA, 1992). Entre outros problemas apresentados, a autora informa que continuam altos os coeficientes de morbi-mortalidade materna, crescem os números de esterilização cirúrgica, abortamento provocado e cerca de $95 \%$ das mulheres que utilizam a pílula como contraceptivo, a adquirem diretamente nas farmácias, sem nenhum acompanhamento pelo serviço de saúde.

Estudo mais recente do Banco Mundial e citado pela OMS, em 1994, concluiu que ainda existem problemas graves na saúde reprodutiva da mulher brasileira: "informação e escolha de anticoncepcionais extremamente limitada, altas taxas de aborto de risco, altas taxas de câncer de colo de útero, grande número de mulheres com quase nenhuma atenção pré-natal; a taxa mais alta do mundo de nascimento por cesariana, e um risco crescente de bem-estar de mulheres e homens, devido a doenças sexualmente transmissiveis e outras infecções do trato reprodutivo" (ORGANIZAÇÃO MUNDIAL DA SAÚDE, 1994).

Em 1990 estimava-se a ocorrência de um aborto de cada oito mulheres brasileiras em idade fértil, perfazendo um total de quase 350 mil abortos mensais no Brasil. Se correta a estimativa, há quase uma década, praticavam-se 4200000 abortos por ano no Brasil, com o agravante da clandestinidade, que eleva de forma significativa a mortalidade materna (ABORTO, 1990). No mundo, mais de 70 mil mulheres morrem anualmente em conseqüência de abortos malfeitos (OMS, 1996), ou seja, realizados clandestinamente, por pessoas não qualificadas que utilizam procedimentos invasivos, com instrumental inadequado.

Devido à clandestinidade, os dados sobre aborto no Brasil não são precisos mas, por projeção do Ministério da Saúde, de cada 100 abortos, pelo menos 25' ocorrem com adolescentes. As gestações em adolescentes quer terminem em aborto ou parto, estão entre as cinco primeiras causas de morte no grupo e a gravidez na adolescência triplicou nos anos 90 em relação aos anos 70 . A atividade sexual que era iniciada entre 19 e 22 anos, hoje ocorre entre 13 e 16 anos e os jovens não têm sido preparados para viver a sexualidade sem o risco da procriação. Das adolescentes que engravidam, 40\% têm o segundo filho num prazo máximo de três anos (GRAVIDEZ, 1996).

No Brasil, a limitação do acesso à informação e à diversidade de métodos contraceptivos faz com que a laqueadura predomine como o método de escolha após um ou dois filhos, muitas vezes realizada em idades precoces e forçadas por cesáreas, das quais, mais da metade são desnecessárias (OMS, 1994). Pesquisas da BEMFAM (1992) e de Berquó (1993) citadas pela SOF (1994) revelaram que pílula e esterilização juntas representam $74,7 \%$ da prática contraceptiva em São Paulo e 85,9\% no Nordeste.

Diante desta realidade é notório que as mulheres continuem enfrentando sérias dificuldades no que diz respeito à sua saúde reprodutiva, e quanto ao planejamento familiar, estas não se limitam à falta de acesso aos meios para regular a fertilidade, faltamlhes também o saber sobre o seu corpo, sobre os seus desejos e sobre suas possibilidades para intervir no processo reprodutivo, para que possam escolher conscientemente entre os diferentes métodos.

\section{CONSIDERAÇÕES FINAIS}

Ao longo deste estudo constatamos que as políticas públicas resultam de uma luta de classes e, embora proponham benefícios sociais, nem sempre garantem na prática a eficácia do seu conteúdo teórico. Quanto ao PAISM, vimos que, a partir de uma proposta norteada por principios éticos, busca corrigir as distorções existentes no campo da saúde reprodutiva e, em particular, em relação aos direitos reprodutivos. Vimos também que a luta pela sua implantação faz parte do esforço pela implantação do SUS, que toma impulso com as últimas Conferências Nacionais de Saúde, mas retrocede na prática das instâncias responsáveis pela sua concretização. As tentativas de ruptura com os princípios do PAISM, demonstram que, apesar das declarações oficiais favoráveis à sua implantação, há flagrantes manobras políticas com o propósito de inviabilizá-lo.

Tratando especificamente do direito à regulação da fertilidade e considerando o contexto histórico em que foram elaboradas as politicas de planejamento familiar no Brasil, é possivel afirmar que, atualmente, ainda existe uma contracepção controlada por interesses econômicos internacionais, 
a rede hospitalar privada, a medicina de grupo e as instituições de planejamento familiar, que facilitam a mercantilização da contracepção, privilegiando métodos de estrito controle médico, como a pílula e a esterilização.

Finalmente, o planejamento familiar, embora representando um passo decisivo em direção à construção da cidadania feminina, na prática, reflete interesses contraditórios que se confrontam numa luta entre as instâncias politicas, econômicas e ideológicas de poder.

\section{REFERÊNCIAS BIBLIOGRÁFICAS}

ABOrto: essa grande epidemia. Consult. méd., n. 4, p. 33, out./dez. 1990.

AVILA, M. B. Direitos reprodutivos: o caos e a ação governamental. In: CORREAA, S., AVILA, M. B. Os direitos reprodutivos e a condição feminina. Recife, SOS Corpo, 1989. p. $17-25$.

AVILA, M.B. Direitos reprodutivos: uma invenção das mulheres, Recife, SOS Corpo, 1992. /Mimeografado/

BEZERRA, J.L. Neoliberalismo: a doutrina de um reino chamado mercado. Rev. Democr., v. 11,n. 114, 1995. (Encarte).

BRAGA, J. C.S.; PAULA, S.G. Saúde e previdência: estudos de política social . 2. ed. São Paulo; HUCITEC, 1986.

BRASIL. Ministério da Saúde. Assistência Integral à Saúde da Mulher: bases de ação programática. Brasília, Centro de Documentação do Ministério da Saúde, 1985.

BRASIL. Ministério da Saúde. Assistência ao planejamento familiar. Brasília, Centro de Documentação do Ministério da Saúde, 1987.

BRASIL. Ministério da Saúde. Assistência ao planejamento familiar. Brasília, Secretaria Nacional de Assistência à Saúde, 1992.

CAMpos, P.M. Políticas neoliberales en salud. Saúde Deb., p.29-32, mar. 1990. (VI Congresso Mundial de Medicina Social).

CONFERÊNCIA NACIONAL DE SAÚDE (CNS), 8, 1986, Brasília, Anais. Brasília: Centro de Documentação do Ministério da Saúde, 1987.

CORREA, S. PAISM: uma história sem fim. Recife, SOS Corpo, 1992. $10 \mathrm{p}$.
COSTA, A. M. O PAISM: uma política de assistência integral à saúde da mulher a ser resgatada. Brasília, 1992.

DOCUMENTO IX Conferência Nacional de Saúde. Rev. Cent. Bras. Est. Saúde, n. 36, p. 4-5, 1992.

FALEIROS, V. P. 0 trabalho da política: saúde e segurança dos trabalhadores. São Paulo, Cortez, 1992.

GRAVIDEZ na adolescência: não dê as costas para isso. São Paulo, SOF/ 1996 / Folder/

LUCENA, M. F. G. Dois mundos: um estudo comparativo sobre os serviços de saúde nas áreas rurais do Brasil e de Cuba, desde os anos 60 até a atualidade. Havana, 1996. 219 p. Tese (Doutorado em Ciências Sociológicas), Faculdade de Filosofia e História, Universidade de Havana.

LUZ, M. T. Notas sobre as politicas de saúde no Brasil de " transição democrática" - anos 80. PHISIS Rev. Saúde Colet..v. 1. n. 1. p. 77-96. 1991.

MARQUES, M. B. A atenção materno-infantil como prioridade política. In: GUIMARÃES, R. Saúde e medicina no Brasil: contribuição para um debate. Rio de Janeiro, GRAAL, 1978. p. 121-46.

NASCIMENTO, A. Municipalização: trinta anos de esperança e frustrações. Tema. Rio de Janeiro: Fundação Oswaldo Cruz, p. 03-06, Nov. 1991.

OMS: 85 abortos por minuto. Súmula, n. 58, p. 3, abr. 1996.

ORGANIZAÇÃO MUNDIAL DE SAÚDE (OMS). PRH. Análise da necessidade $e$ introdução de anticoncepcionais no Brasil. Brasília, 1994. (Relatório de uma análise colaborativa feita pelo Ministério da Saúde/ COMI/ CEMICAMP e representantes do Coletivo Feminista Sexualidade e Saúde e a União Brasileira de Mulheres).

PACHECO, M.V.A.P. Racismo, machismo e planejamento familiar. 2.ed. Petrópolis, Vozes, 1981.

RODRIGUES, G. de C. Planejamento familiar. São Paulo, Ática, 1990.

SEMPRE VIVA ORGANIZAÇÃO FEMINISTA (SOF). Esterilização feminina. São Paulo, 1994. v.1. (Série Saúde e Direitos Reprodutivos).

SOUZA, B. M. Saúde: a ambivalência das políticas. Rev. CEBRAP, n. 29, p.23 - 36, 1978.

XAVIER, D. et al. Questões femininas para a ordem médica. In: LABRA, M. E. (Org.). Mulher, saúde e sociedade no Brasil. Petrópolis, Vozes, 1989,. p. 204322. 